(cf. following paragraph), and this may also be true of the corresponding reaction in solution :

$$
\begin{aligned}
& \mathrm{X}_{2}+h \nu \rightarrow 2 X . ; \quad>\mathrm{C}=\mathrm{C}<+X . \rightarrow>\stackrel{\text { C }}{\stackrel{\mathrm{C}}{\mathrm{C}}-\mathrm{X}}
\end{aligned}
$$

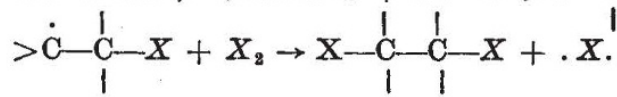

Homolytic reactions involving free radicals ${ }^{13}$ (compare Table of Types of Substitution) exhibit some similarity to the heterolytic processes in which electrophilic reagents are concerned, because free radicals generally have depleted electron shells and tend to share an extra electron: for example, $\mathrm{C}_{6} \mathrm{H}_{8} .+\mathrm{Cl}-\mathrm{CCl}_{3} \rightarrow \mathrm{C}_{6} \mathrm{H}_{5}-\mathrm{Cl}+. \mathrm{CCl}_{3}$. Their electrophilic character is most clearly shown in the addition reactions with olefins. In the so-called 'normal' addition of hydrogen bromide to the alkylethylenes, the proton adds preferentially to the unsaturated carbon atom bearing the smaller number of alkyl groups (cf. Markownicoff's rule), for example,

$$
\begin{aligned}
& \left(\mathrm{CH}_{3}\right)_{2} \mathrm{C} \cong \mathrm{CH}_{2}+\mathrm{H} \mid-\mathrm{Br} \rightarrow \\
& \left(\mathrm{CH}_{3}\right)_{2} \stackrel{+}{\mathrm{C}}-\mathrm{CH}_{3}+\overrightarrow{\mathrm{Br}} \rightarrow\left(\mathrm{CH}_{3}\right)_{2} \mathrm{C}(\mathrm{Br}) \cdot \mathrm{CH}_{3} \text {. }
\end{aligned}
$$

Likewise, in the peroxide-catalysed reaction ('abnormal' addition), the addition is initiated by the attack of a bromine atom at the point of higher electron density :

$$
\begin{aligned}
\left(\mathrm{CH}_{3}\right)_{2} \mathrm{C}=\mathrm{CH}_{8}+. \mathrm{Br} \rightarrow & \left(\mathrm{CH}_{3}\right)_{2} \dot{\mathrm{C}}-\mathrm{CH}_{2} \mathrm{Br} \stackrel{\mathrm{HBr}}{\longrightarrow} \\
& \left(\mathrm{CH}_{3}\right)_{2} \mathrm{CH}-\mathrm{CH}_{2} \mathrm{Br}+. \mathrm{Br} .
\end{aligned}
$$

It must be emphasized, however, that this analogy between neutral radicals and electrophilic reagents has definite limitations. Thus, it is well known that aromatic substitution reactions of neutral radicals, for example, $\mathrm{Ph}$. $+\mathrm{H}_{\text {. }} \mathrm{C}_{6} \mathrm{H}_{4} R \rightarrow \mathrm{Ph} \mathrm{C}_{6} \mathrm{H}_{4} R+. \mathrm{H}$, do not exhibit the usual orientation effects associated with the heterolytic reaction. This is understandable, for the 'orienting' influence of a substituent group is due to its transmitted polar effects, which are largely dependent on the demands of the reaction involved, and it is reasonable to suppose that the electron displacements which are a necessary condition for an oriented heterolysis are of less importance in homolysis.

It has been shown that the Cannizzaro reaction ${ }^{14}$ exhibits peroxide catalysis and other characteristics of a radical process, and the observations can be satisfactorily accounted for on the basis of a mechanism involving the radicals $R \mathrm{CO}$ and $R \mathrm{CHOH}$, both of which are formed from the aldehyde RCHO by univalent oxidation and reduction respectively.

\section{USE OF SCIENCE AND SCIENTIFIC WORKERS IN THE WAR}

$7 \mathrm{HE}$ sessions during the morning and afternoon of the last day of the Conference organized by the Association of Scientific Workers and held in London during January $10-11$ dealt with the two related topics: the utilization of scientific personnel, and the application of scientific knowledge to production and Sorvices problems.

After an introductory address by Prof. S. Chapman, in which he compared the use of science in the War of 1914-18 and in this War, Prof. W. Wardlaw spoke on the working of the Central Register. He stated that the Register has come in for a good deal of criticism but that it should be borne in mind that nearly all the persons enrolled on the Register are already in useful work from which they can only move to more important posts. The Register is intended to be a complete record of the higher administrative, professional and technically qualified personnel of Great Britain, whether employed or not. The number of engineers and scientific workers on the Register has risen from 65,000, in May 1940 , to 167,000 , in December 1941. It has never been the function of the Register to determine how scientific and technical knowledge should best be used in the prosecution of the War; its purpose is to meet demands for technical personnel for war purposes and to allocate the available supply in cases of scarcity. He pointed out that technical officers of full professional standing are now at the head of each section, and referred to the formation of the Technical Personnel Committee under the leadership of Lord Hankey.

Prof. Wardlaw then dealt with the new procedure of progressive de-reservation being conducted by the District Manpower Boards of the Ministry of Labour. He stated that steps are being taken to ensure that anyone with technical qualifications of Central Register standard, if not already deferred by virtue of his work, will be dealt with by the Register and placed in work which makes full use of his technical capacity, whether in the Forces or not.

Mr. E. D. Swann, of the executive committee of the Association of Scientific Workers, presented the results of inquiries by the Association into the position in the main industries in the country. It has been found that many scientific workers and engineers are not being used on war work but are engaged instead on development and design for the period of post-war competition. Others who are nominally engaged on war work have insufficient to occupy their time fully. He stated that the Essential Works Order is being used to hold redundant staff, that no mechanism exists for providing partly occupied laboratories with further problems, and that there is considerable duplication of work in laboratories and design departments of similar undertakings. He pointed out the need for provision for the proper pooling of information, including trade secrets. Another weakness is the notable lack of contact between the design departments of the Ministries and the design and production departments in industry. It has been found that criticism of designs from the point of view of speed and economy of manufacture is not encouraged. The Association has collected enough evidence of this sort to press for an investigation into the utilization of our technical resources by the Select Committeo on National Expenditure.

Mr. Swann then dealt with the Association's proposal that a Technical Planning Committee should be set up under the Production Executive. This Committee would deal with the technical resources of Great Britain in the same manner as the existing Industrial Capacity and Materials Committees deal with their respective resources. In this scheme it is essential that this Committee be given executive powers. The Association of Scientific Workers, as it is composed of working men of science and technicians, is in a position to know how effective is the present organization in practice, and it knows that it is not 
working satisfactorily. Central planning of scientific work is essential, and scientific committees must have contact with working men of science on the job.

The position inside the Services was considered by two speakers at some length. Prof. H. Levy stressed the vital importance of having trained men of science inside the Armed Forces. He wants to see scientific men actually at the front who could bring back all kinds of relevant information of a technical nature. $\mathrm{He}$ pointed out that in Great Britain scientific educa. tion is not considered in selecting personnel for the higher commands. He stressed that not only military men should be chosen, but also scientific men who have had knowledge and experience of military matters.

Mr. F. Morgan, an operational research scientist attached to an R.A.F. command, provided a firsthand review of this type of work. He described how a number of workers are drafted from research to battle centres to ensure that the best use is made of their inventions. Now these men have acquired an operational outlook and can tell their research establishment what the Command most needs; that is, they can initiate research on new equipment and suggest modification to existing equipment. But their most useful function lies in helping Command to make the best use of equipment provided. This involves education of the people who use it, statistical analysis of the ways in which it can be used, and general investigation and the arrangement of tests. $\mathrm{He}$ pointed out in the second connexion that his Command now analyses everything numerically from efficiency of weapons to comparison of tactics. As a result, scientific workers are able to suggest and invent mancuvres - they are no longer "amateur strategists".

Mr. Morgan emphasized the importance of methods of communication in this War, and stated that automatic equipment has not been exploited as it should. He illustrated how in the problem of night fighting, mathematicians, physicists, biochemists, psychologists and physiologists are all nooded. $\mathrm{He}$ hopes that there will be a permanent place in the Services for such scientific field work, and suggested the formation of a central research body for all the Services, and a greater measure of inter-Service liaison. It was significant that he pointed out from the other side the tenuous connexion between operational and industrial scientific workers. Further, he asked for closer contact with their colleagues in all Allied countries. His was a thoughtful paper which made a deep impression on the Conference. In pointing out the not inconsiderable risks which this type of work involves, he expressed the grievance that there is no special compensation for dependants in the event of casualties sustained on flying duties and that promotion is slow relative to the Service rate.

A most refreshing contribution was that of $\mathbf{M r}$. T. Halse, of the Industrial Committee of the Association. After citing several of the more extreme instances where the present lack of planning has led to marked inefficiency, he dealt with the ways in which the scientific worker in industry could help better the situation. Most important of these is participation in Production Committees, whether actually in the factory or regionally. He underlined the need for the scientific workers themselves to be organized to get the best results in this direction.

There were numerous papers in which were instanced in detail and from first-hand experience bad examples of misuse or inefficient utilization of technical knowledge. Mr. R. E. Foster reported that in his laboratory, which is attached to a large aeroengine factory, most of the woork consists in rechecking materials which have already been sub. jected to Air Ministry inspection and release. There is also a considerable amount of slack time in his laboratory, although members have been refused their release on the grounds of pressure of work. When dealing with the position in the research department of this firm he mentioned that there is insufficient allocation of funds for new equipment, lack of space, and inadequate pay for the research staff. $\mathrm{He}$ and his colleagues believe that production is being severely handicapped by lack of scientific planning and management, and by lack of co-operation between management and staff, and between staff workers and manual workers. Continuing, he suggested remedies, emphasizing the part of Production Committees, and calling for the national pooling of all resources of development and research and full inter. change of all experimental and production data, regardless of vested interests.

The present situation in the chemical industry was considered by Mr. A. Dooley. Whereas the engineering industry is mainly based on mass-production methods, the chemical industry demands the existence of teams of workers, embracing manual, scientific and clerical workers. There should be no arbitrary breaking up and re-assembling of such groups, and replacement personnel should be specially trained to maintain the efficiency of the group as a whole. We can expect that the extension of the War will create a demand for substitute products and the reclamation of used material on a large scale. This will bring into active war production sections of the chemical industry which have been kept more or less in reserve,

Mr. Dooley dealt especially with the rubber situation. At the moment, in Great Britain, we reclaim only one fifth of the proportion reclaimed in the United States, and an American authority has estimated that it would take 18-24 months to construct new plants. Our capacity for synthetic replacement manufacture appears to be negligible, but we could draw on the extensive experience of the United States and the U.S.S.R. Dove-tailed planning would be necessary, and electric power on a large scale may be essential. With regard to the technical development of substitute and reclaimed material, it is important to ensure close collaboration between the Services, rubber users, research associations and the chemical industry, and this applies also to resins and textile substitutes. The problem is on too large a scale for it to be carried through effectively by haphazard methods.

A notable set of contributions were those which dealt with the protection of the health of the industrial worker. Dr. T. O. Garland in a forceful speech directed attention to the comparative indifference with which many managements have treated this question in peace-time. Recently the British Medical Association has issued a report which advocates medical supervision of workers in every factory, large or small, which should aim at reducing the general sickness rate as well as the accident rate. Dr. Haden Guest has stated that the number of medical men in industry is a very small proportion of those in the Services. Dr. Garland asked for medical men to be called up into industry as well as into the Forces. With the building of large munition factories the situation is aggravated, because the general practi- 
tioner service is not sufficient to cope with this extra work. Dr. R. O. Stanford supported this suggestion, quoting from his own experience as a medical officer at a large factory. He sketched a plan for massradiography of workers in order to diagnose the early stages of tuberculosis, a disease which is on the increase. Dr. D. McClean, of the Lister Institute, stressed in this connexion that all milk sold to the public should be safe (that is, not infected) milk.

The Oxford vaporizer, a simple apparatus for administering anæsthetics under battle conditions, was described by Dr. K. Mendelssohn, of the Clarendon Laboratory, Oxford. This vaporizer is now being mass-produced at a cost four times lower than that if bench-produced. He stressed the need for closer contact between medical men and men of science, between clinical and laboratory workers.

Dr. S. E. Hollingworth, of the Geological Survey, illustrated how geologists are often not called in when sites for factories, camps and air-raid shelters are decided upon. This has led to considerable waste when the site is badly chosen in relation to drainage and water-supply. Dr. N. F. M. Henry, of the Department of Mineralogy, Cambridge, asked for a larger place in the war effort for geologists, stating that the British Army has only two geologists. He also discussed the Malayan situation and the consequent need for using the other mineral resources of the Allied countries.

There were many other speakers in the discussions, and they represented between them a considerable cross-section of industry. Mr. F. M. H. Markham, of the Central Register, answered some of their points regarding the utilization of personnel. Although he mentioned some cases where action is being taken or being considered, the Conference seemed quite definitely to show the need on the part of official committees for consulting the junior scientific worker.

The Conference was summed up most ably wy Prof. J. D. Bernal. Starting on a note of urgency, he appealed for an absence of complacency on the part of men of science with regard to what Great Britain is doing. The suggestions which were put forward at the Conference would be taken up with the Ministries of Supply and Labour, but this would not be done without opposition. This opposition would come from industry and from the Government. The first is due to the prevalence of pre-war competitive ideas, while the second is purely conservative opposition to new ideas. However, the scientific way of doing things is forcing its way against that opposition, although the attitude in many of the departments is equivalent to sabotage. Dealing with the proper utilization of our man-power, he emphasized that the only consideration in the selection and posting of personnel should be ability. We should bo blinding ourselves to facts if we thought this was so at present. He referred to the contributions in the Conference which had shown a widespread feeling that these scientific workers are not fully occupied, not doing the work they can most usefully do. The mechanism that exists at present is certainly not adequate if this situation holds. The Conference is not passing any resolutions ; it is instead going to take appropriate action. The Association of Scientific Workers will collate the information and suggestions, and send delegations to appropriate Ministries. Scientific workers are at last co-operatively conscious of the job they have to do in society, and they will do it, and not stop doing it, when the War is won.

\section{OBITUARIES}

\author{
Dr. Walcot Gibson, F.R.S.
}

The death of Walcot Gibson will recall to many the memory of a many-sided, alert and virile personality. Born in 1864, he went from Bromsgrove School to Mason College (now the University of Birmingham) at a time when Lapworth, fresh from his triumphs in the south of Scotland, had been appointed to the chair of geology. Young Gibson, his first student, fell under the master's spell and his admiration for Lapworth remained with him as an inspiration throughout his career.

Following on a course of study at the Royal College of Science, Walcot Gibson undertook private geological work in South Africa during 1889-91 and in East Africa during 1891-93. The rest of his active life was spent in Great Britain in the service of the Geological Survey. Appointed temporary assistant geologist in 1893, he became geologist in 1901, district geologist in 1913, and in 1920 assistant director in charge of the Survey work in Scotland. In 1925 he retired and elected to live at Hythe, where he found leisure and opportunity to indulge in his love of gardening and painting. One of his chief pleasures was to welcome his old friends and former colleagues to his new home, and none who visited him but left with an increased regard for his sanity of outlook and balanced judgment on scientific matters. Soon after the outbreak of war ho had to leave Hythe, and he died in Cambridge on November 28.

Walcot Gibson was part author of numerous Geological Survey memoirs dealing with the structure, succession and economic resources of many important coalfield areas in the Midlands and in South Wales : for example, Stoke-on-Trent (1902, with second editions in 1905 and 1925), North Staffordshire (1905), South Derbyshire and Nottinghamshire (1908), North Derbyshire (1913), South Staffordshire and Warwick (1919), Abergavenny (1902), Pontypridd (1903 and 1917), and Merthyr Tydfil (1904). He had learnt from Lapworth the necessity for careful and exact mapping and the value of what his exemplar termed the "zonal method of stratigraphy". He applied these lessons with scrupulous care to his studies of the detailed stratigraphy and palæontology of the Midland coalfields, and through his published works and the many personal contacts he made in the mining world' he played an important part in guiding their economic development. A notable achievement in this direction was his study of the "Concealed Coalfield of Yorkshire and Nottinghamshire" (1913).

While much the greater part of Gibson's work was of an intensive, detailed character which perhaps only the specialist can fully appreciate, he won for himself many warm admirers among a wider public by the publication in 1920 of his book on "Coal in Great Britain". In this volume he brought together in a compact and attractive form the essential information regarding the British coalfields, and its success in filling a long-felt want may be gauged by the fact that a revised and enlarged edition appoared in 1925 .

Walcot Gibson's services to science, particularly in the field of economic geology, were recognized by the award in 1924 of the Murchison Medal of the Geological Society and in 1925 by his election to the fellowship of the Royal Society.

M. Macaregor. 